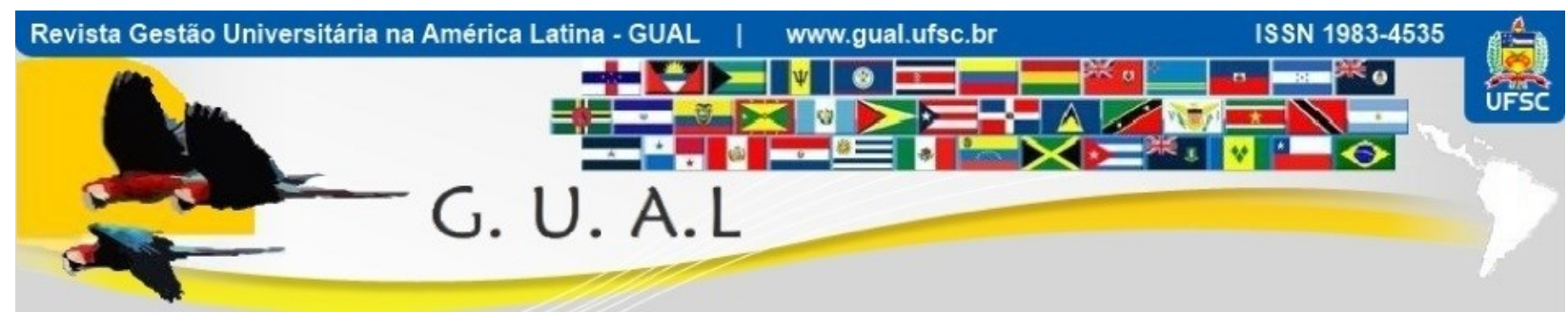

DOI: http://dx.doi.org/10.5007/1983-4535.2017v10n2p91

\title{
ANÁLISE ENVOLTÓRIA DE DADOS PARA AVALIAÇÃO DA EFICIENNCIA FINANCEIRA DOS CURSOS DE GRADUAÇÃO DE UMA IES COMUNITÁRIA
}

\section{DATA ENVELOPMENT ANALYSIS FOR FINANCIAL EFFICIENCY EVALUATION OF UNDERGRADUATION PROGRAMS OF A HEI COMMUNITY}

Cleyton de Oliveira Ritta, Doutorando Fundação Universidade Regional de Blumenau - FURB cleytonritta@gmail.com

Kátia Aurora Dalla Líbera Sorato, Mestra Universidade do Extremo Sul Catarinense - UNESC kal@unesc.net

Nelson Hein, Pós-Doutor Fundação Universidade Regional de Blumenau - FURB hein@furb.br

Recebido em 12/dezembro/2015

Aprovado em 20/fevereiro/2017

Sistema de Avaliação: Double Blind Review

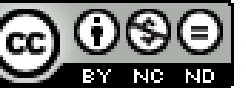

Esta obra está sob uma Licença Creative Commons Atribuição-Uso. 


\title{
ANÁLISE ENVOLTÓRIA DE DADOS PARA AVALIAÇÃO DA EFICIÊNCIA FINANCEIRA DOS CURSOS \\ DE GRADUAÇÃO DE UMA IES COMUNITÁRIA \\ DOI: http://dx.doi.org/10.5007/1983-4535.2017v10n2p91
}

\section{RESUMO}

O objetivo geral da pesquisa é avaliar a eficiência financeira dos cursos de graduação de uma Instituição de Ensino Superior (IES) comunitária. A pesquisa caracteriza-se como descritiva, do tipo estudo de caso com abordagem quantitativa por meio da modelagem matemática de Análise Envoltória de Dados (DEA). Os resultados da pesquisa mostraram que 7 cursos são eficientes $(50,00 \%)$ e 7 cursos são considerados ineficientes $(50,00 \%)$. A técnica DEA revela que para buscar a eficiência financeira, os cursos ineficientes necessitam aumentar receitas e diminuir despesas administrativas e outras despesas operacionais. Diante dos resultados, conclui-se que as ações gerenciais indicadas pela DEA requerem uma reflexão crítica por parte dos gestores. A primeira ação, que envolve a possibilidade de aumento de receitas, está vinculada, principalmente, às condições de infraestrutura universitária disponível e aos fatores socioeconômicos da região e de potenciais alunos; além da observância dos preços praticados por cursos concorrentes. A segunda ação, relativa aos gastos operacionais, cabe uma discussão sobre a efetiva necessidade de realização da despesa e sobre o desenvolvimento de políticas gerencias que aumentem o controle de gastos para evitar desperdícios, abusos e excessos de consumo sem justificativas cabíveis.

Palavras-chave: Desempenho financeiro. Instituição de ensino superior (IES). Análise envoltória de dados (DEA).

\begin{abstract}
The overall objective of the research is to evaluate the financial efficiency of under graduate programs at a community Higher Education Institution (HEI). The research is characterized as descriptive case study with a quantitative approach through a mathematical modeling of data envelopment analysis (DEA). The survey results showed that 7 programs are efficient $(50.00 \%)$ and 7 courses are considered inefficient $(50.00 \%)$. The DEA technique reveals that in order to seek financial efficiency, inefficient programs need to increase their revenue and reduce administrative expenses and other operating expenses. Given the results, it is concluded that the management actions indicated by DEA require a critical reflection on the part of managers. The first action, which involves the possibility of increasing the revenues, is linked mainly to university infrastructure conditions available and to the socioeconomic factors of the region and potential students; in addition to complying with prices charged by competitor programs. The second action, which is related to operating expenses, is a discussion on the real necessity of spending and the development of managerial policies that increase the controls over the expenses to prevent waste, abuse and excess consumption without reasonable justification.
\end{abstract}

Keywords: Financial performance. Higher education institution (HEI). Data envelopment analysis (DEA). 


\section{INTRODUÇÃO}

A análise do desempenho organizacional é um dos instrumentos gerenciais que auxiliam as organizações na condução dos negócios. Por meio de medidas controle para avaliação de desempenho, as organizações conseguem monitorar, comparar e avaliar as atividades organizacionais. Segundo Catelli (2001), a avaliação do desempenho é um processo de julgamento com base em informações gerenciais para que o usuário compreenda a situação organizacional.

A contabilidade é uma das principais áreas gerenciais provedoras de informações para a avaliação do desempenho organizacional. Segundo Gasparetto (2004) cabe à contabilidade, o fornecimento de informações gerenciais para que o tomador de decisão conduza as ações gerenciais de curto e longo prazo, com vistas a promover a continuidade dos negócios. As informações contábeis são elementos relevantes para os gestores, proprietários e investidores, pois evidenciam a situação patrimonial, econômica e financeira das organizações.

Schmidt, Santos e Martins (2006) observam que a avaliação de desempenho organizacional é um processo complexo que tende a se elevar ainda mais no gerenciamento das entidades; uma vez que se configuram como organismos dinâmicos e multifuncionais que interagem com pessoas e com outras entidades em um ambiente instável e competitivo. Por isso, surge a necessidade de indicadores de desempenho para controlar o desenvolvimento das atividades e para tornar as decisões gerenciais mais racionais.

Dentre as organizações dinâmicas e complexas destacam-se as Instituições de Ensino Superior (IES). Segundo Andrade (2002), as IES caracterizam-se por entidades organizacionais complexas, uma vez que possuem metas institucionais amplas, apresentam forte dependência de habilidades individuais, têm profissionais com alto grau de autonomia e contemplam processos gerenciais que envolvem um grande número de unidades e atores. Portanto, gerenciar tais fatores é questão fundamental para maximizar o desempenho organizacional e aumentar a competitividade nos serviços ofertados.

A gestão das IES demanda por indicadores de desempenho para mensurar padrões de atividades, possibilitar o autoconhecimento institucional e assegurar a continuidade dos negócios. Pessoa (2000) menciona que no Brasil, as IES passam por um período de mudança que exige maior agilidade e flexibilidade nos processos gerenciais para possibilitar o cumprimento do seu papel social. Para tanto, as IES precisam se ajustar as novas necessidades 
de gestão para que atendam às transformações econômicas, tecnológicas, políticas e sociais da sociedade.

O desempenho financeiro é uma das principais preocupações referente à avaliação de desempenho organizacional para as IES. A sustentabilidade financeira, principalmente para as IES privadas ou comunitárias, é uma preocupação constante para os gestores universitários, uma vez que os alunos representam a principal fonte de recursos. Segundo a Associação Brasileira de Mantenedoras do Ensino Superior - AMBES (2014), em pesquisa realizada entre os anos de 2008 e 2012 com pequenas e médias IES privadas, os principais fatores que afetam a gestão financeira das IES são aumento da inadimplência, evasão escolar, queda na taxa de matrículas, deterioração financeira e dificuldades na captação de alunos. Acredita-se que esses fatores também são relevantes para as demais IES privadas por agravar significativamente a situação financeira das instituições; pois os gastos gerais estão cada vez mais elevados com infraestrutura e despesas operacionais. As receitas, por sua vez, estão cada vez mais ameaçadas pelo aumento da concorrência que oferecem novas vagas com preços mais competitivos e da inadimplência nos serviços prestados.

Diante desse cenário, surge a seguinte pergunta de pesquisa: Qual é a eficiência financeira dos cursos de graduação de uma Instituição de Ensino Superior (IES) comunitária? Para responder essa pergunta, o objetivo geral da pesquisa é avaliar a eficiência financeira dos cursos de graduação de uma Instituição de Ensino Superior (IES) comunitária do sul do Brasil.

$\mathrm{Na}$ literatura, estudos anteriores também avaliaram o desempenho organizacional de unidades internas de IES, como cursos de graduação, centros e departamentos acadêmicos. Algumas discussões sobre o tema ocorreram nas pesquisas de Mello et al. (2004), Alencastro e Fochezatto (2006), Cavalcante e Andriola (2012), Rosano-Peña (2012), Giacomello e Oliveira (2014) e Soliman et al. (2014). Esses estudos mediram a eficiência de unidades universitárias, considerando aspectos técnicos e operacionais das áreas de ensino, pesquisa e extensão, por meio da modelagem matemática de Análise Envoltória de Dados (Data Envelopment Analysis - DEA).

Com base nesses estudos, a presente pesquisa se justifica e se diferencia ao mensurar a eficiência organizacional com base em variáveis financeiras que envolvem receitas e despesas operacionais de cursos de graduação de uma IES. O argumento de pesquisa tem por fundamento que a crescente oferta de vagas no ensino superior causa a) aumento da 


\section{ANÁLISE ENVOLTÓRIA DE DADOS PARA AVALIAÇÃO DA EFICIÊNCIA FINANCEIRA DOS CURSOS \\ DE GRADUAÇÃO DE UMA IES COMUNITÁRIA \\ DOI: http://dx.doi.org/10.5007/1983-4535.2017v10n2p91}

concorrência, b) maiores dificuldades de gestão, c) maiores exigências nos níveis de qualidade nos serviços prestados e d) queda nos preços dos serviços ofertados. Por isso, essa pesquisa corrobora com o tema ao investigar a eficiência financeira de cursos graduação como instrumento de apoio à gestão universitária e como forma de identificar os cursos com melhores práticas de gestão e que podem servir com benchmark interno institucional. Sendo assim, esta pesquisa contribui com novas evidências com relação à discussão da eficiência nas IES com vistas à manutenção das atividades de ensino, pesquisa e extensão.

\section{REFERENCIAL TEÓRICO}

Esta seção apresenta aspectos sobre desempenho financeiro, avaliação de desempenho nas IES e estudos anteriores relacionados ao tema de pesquisa.

\subsection{DESEMPENHO FINANCEIRO}

$\mathrm{O}$ ato de avaliar é um processo de análise e de julgamento de qualquer situação ou objeto que exija uma tomada de decisão para que se consiga atingir um objetivo. O processo de avaliação de desempenho contempla um conjunto de critérios, conceitos, crenças, valores e habilidades que são utilizados pelo avaliador para que se obtenha coerência e racionalidade nos julgamentos e eficiência nos resultados (PEREIRA, 2001).

No contexto organizacional, a avaliação desempenho deve estar vinculada sistematicamente e culturalmente ao sistema de gestão, uma vez que implica em consequências positivas e negativas no processo gerencial. Atkinson et al. (2000) esclarecem que a avaliação do desempenho organizacional possibilita um vínculo entre o planejamento e controle de gestão. O planejamento representa os objetivos estratégicos almejados e o controle caracteriza-se como processos de gestão que servem para assegurar que objetivos estratégicos planejados sejam alcançados.

De acordo com Slack, Chambers e Johnston (2002), a avalição de desempenho é um pré-requisito para a melhoria contínua das atividades organizacionais. Um sistema de avaliação de desempenho propicia a distinção de aspectos internos e externos de cada atividade. Além disso, identifica o impacto das atividades na contribuição do desempenho global. Outra função importante da avaliação de desempenho consiste em possibilitar o aperfeiçoamento das atividades para promover a competitividade da organização. 


\section{ANÁLISE ENVOLTÓRIA DE DADOS PARA AVALIAÇÃO DA EFICIÊNCIA FINANCEIRA DOS CURSOS \\ DE GRADUAÇÃO DE UMA IES COMUNITÁRIA \\ DOI: http://dx.doi.org/10.5007/1983-4535.2017v10n2p91}

O sistema de avaliação de desempenho é composto por indicadores que se configuram como medidas quantitativas ou qualitativas desenvolvidas para caracterizar as atividades organizacionais. Kaplan e Norton (2000) mencionam que a utilização de indicadores permite averiguar o gerenciamento da estratégia. Essa ação contribui para a otimização do desempenho de uma unidade de negócio ou de toda a organização, corroborando para a formação de instituições sustentáveis. Galvão, Corrêa e Alves (2011) ressaltam que os indicadores de desempenho devem refletir uma relação de causa e efeito no ambiente organizacional e sua análise deve considerar a interação entre todas as áreas de gestão. Os indicadores de desempenho também proporcionam o autoconhecimento de aspectos gerenciais que promovem a melhoria contínua e fornecem informações significativas sobre a situação organizacional.

As dimensões da avaliação de desempenho organizacional são amplas. Portanto, para fins deste estudo destaca-se a dimensão de desempenho financeiro que contempla aspectos monetários dos recursos consumidos para a geração de produtos ou prestação de serviços. De acordo com Pereira (2001), o desempenho financeiro caracteriza-se pela atividade operacional que consome insumos e se configura como gastos operacionais. Com o processo de transformação dos insumos, obtém-se a produção de bens e a prestação de serviços que devem possuir valores superiores aos gastos incorridos, para dessa forma conseguir o lucro.

Os indicadores de desempenho financeiro são instrumentos de diagnóstico da situação financeira que apontam as condições de despesas, custos, receitas, caixa, lucro ou prejuízo das organizações. A base para elaboração desses indicadores é a contabilidade que tem a função de registrar dos fatos ocorridos que afetam o patrimônio das entidades; com vistas a mensurar o resultado das operações e fornecer aos usuários informações que contribuam para avaliação de desempenho e para o processo decisório (HENDRIKSEN; VAN BREDA, 1999; IUDÍCIBUS, 2010).

A contabilidade é uma das principais linguagens de negócios e se caracteriza como uma importante fonte de informações para a avaliação de desempenho organizacional. Os relatórios contábeis permitem a compreensão de diversos aspectos organizacionais, principalmente, no que tange ao desempenho financeiro para que gestores, proprietários, investidores, credores entre outros, para que consigam avaliar os investimentos realizados (HENDRIKSEN; VAN BREDA, 1999; IUDÍCIBUS, 2010). 
Segundo Assaf Neto (2012, p. 110), a análise dos relatórios contábeis possibilita a identificação do "desempenho econômico-financeiro de uma empresa em determinado período passado, para diagnosticar, em consequência, sua posição atual e produzir resultados que sirvam de base para a previsão de tendências futuras". Por meio, dos relatórios contábeis, o avaliador deve tomar decisões financeiras que promovam a perpetuidade dos negócios e que criem valor para as organizações.

As informações contábeis propiciam a construção de indicadores de desempenho financeiros que revelam a realidade organizacional, as estratégias e os planos traçados. Esses indicadores são calculados mediante relações entre contas ou grupos contábeis para evidenciar determinado aspecto da situação econômica ou financeira (MATARAZZO, 2010). O resultado dessas relações possibilita acompanhamento do desempenho financeiro dos negócios, além da realização de inferências sobre limitações e potencialidades futuras das organizações.

Assaf Neto (2012) observa que também é preciso utilizar os indicadores de desempenho financeiro para fazer análises comparativas de caráter temporal e entre organizações, para a obtenção de uma avaliação de desempenho mais abrangente e que permita a compreensão do desempenho de concorrentes, setores e de padrões de mercado. Com isso, os usuários dos indicadores de desempenho conseguem perceber o impacto de fatores internos e externos que afetam a organização. Assim, contam com condições mais favoráveis para se criar medidas preventivas e corretivas para garantir o alcance dos objetivos propostos.

A avaliação de desempenho financeiro é um instrumento gerencial que proporciona que as melhores práticas de gestão, no uso de recursos disponíveis, sejam executadas de modo eficiente. Esse instrumento tem como foco a melhoria contínua das atividades organizacionais, por meio do alinhamento entre recursos econômicos, processos de gestão e capital humano.

\subsection{AVALIAÇÃO DE DESEMPENHO FINANCEIRO NAS IES}

As IES são organizações de prestação de serviços que podem ser credenciadas como Faculdades, Centros Universitários e Universidades (BRASIL, Decreto n. 5.773/06). Como enquadramento administrativo, as IES configuram-se em: a) públicas - mantidas pelo poder público, b) particulares - mantidas por uma ou mais pessoas jurídicas de direito privado, c) 
comunitárias - mantidas por grupo de pessoas físicas ou por uma ou mais pessoas jurídicas sem fins lucrativos, d) confessionais - mantidas por grupo de pessoas físicas ou por uma ou mais pessoas jurídicas que atendem a orientação confessional e com ideologia específica sem fins lucrativos e e) filantrópicas - na forma de lei (BRASIL, Lei n. 9.394/96; Lei n. 12.020/09).

As IES são responsáveis pelo desenvolvimento intelectual, cultural, tecnológico e econômico da sociedade. Essas instituições, principalmente as Universidades, prestam serviços na área de ensino, pesquisa e extensão e, assim, disseminam o conhecimento para a sociedade. Essa ampla área de atuação faz dessas instituições entidades complexas, uma vez que têm múltiplos objetivos, dependem de uma infraestrutura diversificada e possuem mão de obra especializada e autônoma no desenvolvimento das atividades.

Com o advento da Lei n. 9.394/96 ocorreu a flexibilização da oferta de ensino superior por instituições privadas. Esse fato promoveu o crescimento do setor privado de ensino e o aumento de vagas em um mercado com demanda reprimida. Por outro lado, as IES tiveram que buscar a eficiência em seus processos de gestão para garantir melhor preço, manter a qualidade e assegurar a melhoria contínua dos serviços prestados. Nesse cenário, segundo Reis e Reis (2013), para se manterem competitivas, as instituições necessitam de uma estrutura organizacional mais enxuta que proporcione uma aproximação entre os níveis de decisão e de execução para permitir o desenvolvimento de estratégias que promovam o alcance dos objetivos propostos com mais agilidade.

Reis e Reis (2013), ainda observam que IES podem ser vistas como um conjunto de processos que estão sequencialmente inter-relacionados e que consomem insumos diversificados como materiais de uso consumo, infraestrutura, mão de obra e conhecimento; que consequentemente, resulta em produtos de conhecimento como formação profissional, produção científica e tecnológica. Por isso, a gestão organizacional das IES deve estar voltada para a sustentabilidade do negócio, por meio do alinhamento dos objetivos acadêmicos, econômicos e sociais.

A gestão das IES contempla elementos complexos (insumos e produtos) que exigem sistemas de controle e de avaliação de desempenho para potencializar o resultado institucional e aumentar a competitividade. Reis e Reis $(2013$, p. 5) mencionam que as IES começam a utilizar "indicadores de avaliação de desempenho diante às pressões competitivas criadas pela globalização, por um consumidor melhor informado e mais exigente". Sampaio e Laniado 
(2009) corroboram ao mencionar que é preciso renovar e modernizar os modelos de gestão universitária para melhorar a racionalidade administrativa, a eficiência na alocação de recursos e a qualificação do quadro de pessoal.

Os indicadores de avaliação de desempenho financeiro nas IES são medidas que refletem os processos de gestão e tem por objetivo monitorar a sustentabilidade financeira e o atendimento das estratégias de curto e longo prazo. A definição de indicadores de desempenho financeiro depende do perfil da organização, das necessidades gerenciais e dos planos estratégicos institucionais. De modo geral, as informações contábeis destacam-se como principais medidas de desempenho financeiro, tais como: a) indicadores de representatividade e de variação - para receitas, custos, despesas e investimentos; b) indicadores de custeio margem de contribuição, margem de segurança e ponto de equilíbrio; c) indicadores de relação com o número de alunos - para receitas, custos, despesas e investimentos; d) indicadores contábeis - de liquidez, de estrutura de capital, de atividades e de lucratividade; e) indicadores orçamentários - variações entre orçado e realizado; e f) indicadores de inadimplência.

Os indicadores de representatividade e de variação mostram a proporcionalidade, o aumento ou a diminuição de contas ou grupo de contas contábeis referentes à estrutura de receitas e de gastos institucionais. Os indicadores de custeio evidenciam o nível de lucratividade alcançada e os níveis receitas necessários para não ocorrer prejuízos. Os indicadores de relação por número de alunos demonstram a razão entre a estrutura de receitas e de gastos institucionais com a quantidade de aluno existente. Os indicadores contábeis revelam o desempenho institucional, conforme a capacidade de pagamento de obrigações, a estrutura das dívidas para o financiamento das operações, os prazos de recebimentos e pagamentos e a lucratividade sobre receita, ativo e capital próprio. Os indicadores orçamentários apresentam as variações entre os valores orçados e realizados de receitas, custos, despesas e investimentos de acordo com o planejamento financeiro. Os indicadores de inadimplência evidenciam o montante e a representatividade dos valores a receber em atraso.

Cruz et al (2009) mencionam que os indicadores de desempenho financeiro são obtidos principalmente nas demonstrações contábeis Balanço Patrimonial e Demonstração do Resultado, que são as bases para o entendimento do desempenho histórico da organização. Os indicadores de desempenho financeiro evidenciam pontos fortes e fracos de gestão que necessitam ser potencializados ou melhorados. A partir deles, é possível estabelecer ações 
gerenciais para promover a definição de investimentos, de estratégias para o crescimento de receitas e de lucros e de redução de custos e despesas.

Os indicadores com abordagem contábil são tradicionais para análise do desempenho financeiro em empresas, mas também podem ser utilizados para a avaliação do desempenho das IES com algumas adaptações, quando necessário. Nesse sentido, Klann et al. (2012) enfatizam que "não existem indicadores melhores para esta ou aquela organização". Portanto, não há um padrão único de indicadores que atenda de modo universal todas as organizações. Logo, cabe a cada organização definir seus indicadores de avaliação de desempenho financeiro de acordo com suas prioridades de planejamento e de controle gerencial.

\subsection{ESTUDOS ANTERIORES}

A literatura na área do ensino apresenta estudos sobre avaliação de desempenho em unidades internas de IES, com o apoio da técnica de modelagem matemática Análise Envoltória de Dados (DEA). A DEA é um instrumento gerencial que serve para mensurar a eficiência de unidades organizacionais no processo de transformação de insumos (inputs) em produtos (outputs) (LINS; MEZA, 2000).

Os pesquisadores Mello et al. (2004) realizaram estudo de análise de desempenho com a utilização do DEA para avaliar necessidade de alocação de vagas docentes em 12 departamentos de ensino do Centro Tecnológico da Universidade Federal Fluminense (UFF). O insumo foi número de docentes alocados nos departamentos e os produtos foram atividades dos professores, número de alunos/hora, produção científica e projetos aprovados. Os resultados evidenciaram que 6 departamentos foram considerados eficientes. Com o uso de restrições aos pesos para permitir o desempate entre os departamentos e a aderência as necessidades do Conselho Universitário da UFF, a modelagem apresentou apenas 1 departamento como eficiente. Os resultados também revelaram que 2 departamentos considerados mais eficientes receberam maior número de vagas segundo critérios internos da UFF.

Alencastro e Fochezatto (2006) avaliaram a eficiência de 34 cursos de graduação de uma universidade privada. Os insumos foram hora-doutor, hora-mestre, hora-outros, evasão e vagas oferecidas. Os produtos foram número de formandos, número de matriculados e receitas. Os resultados apontaram que um grupo de 11 cursos permaneceu, ao longo do tempo, no nível máximo de eficiência. De forma semelhante, constatou-se que houve um grupo de 7 
cursos que, ao longo do tempo, permaneceu sempre ineficiente. Os resultados também mostraram problemas comuns aos cursos menos eficientes, como a necessidade de aumento das receitas. Consequentemente, perceberam que essa necessidade está relacionada com a evasão, ao número de alunos matriculados e fatores macroeconômicos.

Cavalcante e Andriola (2012) avaliaram 30 cursos de graduação da Universidade Federal do Ceará (UFC), no período de 2006 a 2009. Os insumos foram número de alunos ingressantes e esforço da capacidade docente. Os produtos foram quantidade de concluintes, quantidade de alunos em monitoria, quantidade de alunos em PIBIC, quantidade de projetos PIBIC, quantidade de alunos em extensão e quantidade de docentes em extensão. Os resultados revelaram um grupo de 9 cursos (30\%) que permaneceram, ao longo do tempo, com nível elevado de eficiência. Por outro lado, um grupo de 5 cursos (17\%) permaneceu, ao longo do tempo, sempre ineficiente.

Rosano-Peña (2012) avaliou a eficiência de 39 unidades organizacionais da Universidade Estadual de Goiás (UEG). Os insumos foram número de funcionários, número de professores, área construída $\left(\mathrm{m}^{2}\right)$ e Índice de Desenvolvimento Humano dos Municípios IDH-M. Os produtos foram projetos de pesquisa registrados, cursos de graduação, cursos superiores de qualificação profissional, cursos de pós-graduação e número de alunos regulares. Os resultados mostraram que 19 unidades foram eficientes e 20 ineficientes. Após a inclusão da variável contexto, IDH-M, o número de unidades eficientes passou para 28 e de ineficientes para 11. Diante dessas alterações, os autores concluíram que a eficiência organizacional não é obra única da gestão e de recursos controláveis pela organização.

Giacomello e Oliveira (2014) avaliaram 20 unidades de ensino de graduação da Universidade de Caxias do Sul. Os insumos foram quantidade de cursos, custo docente, quantidade de créditos oferecidos e outras despesas. Os produtos foram quantidade de alunos, quantidade de créditos contratados e receitas dos cursos. Os resultados indicaram que apenas uma única unidade foi considerada eficiente. As demais, para chegarem à eficiência, teriam que aumentar todos os seus produtos e manter fixo o montante de insumos. Com a categorização dos níveis de eficiência, 3 empresas foram consideradas com alta eficiência, 13 com média eficiência e 4 com baixa eficiência. Dentre as que apresentaram baixa eficiência, os resultados sugeriram o aumento do número de alunos como principal medida para melhorar a eficiência. 


\section{ANÁLISE ENVOLTÓRIA DE DADOS PARA AVALIAÇÃO DA EFICIÊNCIA FINANCEIRA DOS CURSOS \\ DE GRADUAÇÃO DE UMA IES COMUNITÁRIA \\ DOI: http://dx.doi.org/10.5007/1983-4535.2017v10n2p91}

Justino, Gomes Jr. e Gomes (2014) avaliaram de forma quantitativa 7 cursos de graduação de uma IES privada. Os insumos foram razão entre alunos ingressantes e formandos e custo com professores. O produto foi o número de alunos concluintes. Os resultados evidenciaram que 4 cursos tiveram eficiência máxima. Após a aplicação da técnica de restrições aos pesos na modelagem, apenas dois cursos foram classificados como eficientes. Os cursos considerados ineficientes tinham como principais características custos elevados de professores e números baixos de ingressantes e concluintes.

Soliman et al. (2014) avaliaram a eficiência de 9 unidades da Universidade Federal de Santa Maria (UFSM) sob as perspectivas de ensino, pesquisa e extensão. Os insumos foram razão entre alunos matriculados e professores e razão entre servidores técnico-administrativos e professores. Os produtos foram número de projetos de pesquisa/extensão e média do Conceito Preliminar de Curso (CPC) dos cursos de cada unidade. Os resultados mostraram que 4 unidades foram consideradas eficientes. Como recomendação para as unidades ineficientes, os autores sugeriram o aumento de número de projetos de pesquisa/extensão e da na nota do Conceito CPC.

Os estudos anteriores tiveram com principal abordagem a mensuração da eficiência por meio de atributos técnicos das áreas de ensino, pesquisa e extensão de cursos de graduação, centros e departamentos acadêmicos. Portanto, a presente pesquisa adiciona à literatura novas evidências empíricas sobre eficiência nas IES, com a utilização de variáveis financeiras para mensurar a eficiência organizacional de cursos de graduação em uma IES comunitária.

\section{METODOLOGIA DA PESQUISA}

Para avaliar a eficiência financeira dos cursos de graduação em uma IES comunitária, realiza-se uma pesquisa: a) de natureza descritiva, pois se descrevem as características da estrutura financeira da organização; b) do tipo estudo de caso, em uma IES credenciada como universidade comunitária; c) de procedimento documental com dados primários, pois se utilizam relatórios contábeis com informações financeiras de receitas e despesas dos cursos da instituição; e c) de abordagem quantitativa, uma vez que se mensura a eficiência financeira por meio da técnica de modelagem matemática de Análise Envoltória de Dados - DEA (MARTINS; THEÓPHILO, 2009). 


\section{ANÁLISE ENVOLTÓRIA DE DADOS PARA AVALIAÇÃO DA EFICIÊNCIA FINANCEIRA DOS CURSOS \\ DE GRADUAÇÃO DE UMA IES COMUNITÁRIA \\ DOI: http://dx.doi.org/10.5007/1983-4535.2017v10n2p91}

A instituição objeto de estudo está localizada na região sul do Brasil. É uma universidade comunitária, de natureza jurídica pública de direito privado. A Instituição caracteriza-se como de grande porte e a) possui aproximadamente 1.400 colaboradores entre docentes e técnico-administrativos e mais de 11.000 alunos de graduação e pós-graduação, b) oferta mais de 60 cursos de graduação de formação do tipo bacharelado, licenciatura e tecnológica e, também c) oferta cursos de pós-graduação em nível de mestrado e doutorado. O nome da IES não é divulgado e os valores das variáveis financeiras do estudo foram alterados, mas manteve-se a proporcionalidade numérica, devido à proteção das informações disponibilizadas. Tais ações visam garantir o sigilo profissional dos dados como requer um estudo científico do tipo estudo de caso. Segundo Flick (2009), a ética na pesquisa implica em proteger dados, evitar danos aos participantes e respeitar perspectivas e privacidades.

A coleta dos dados considerou as variáveis financeiras dos cursos de graduação do ano de 2014. Inicialmente, contatou-se a Pró-Reitoria de Administração e Finanças para explicar o interesse da pesquisa e solicitar autorização, cujo retorno foi positivo. Em seguida, contatouse o Gerente de Contabilidade e Finanças para solicitação das informações necessárias para o estudo. Após as conversas iniciais, formalizou-se o pedido de pesquisa por meio de Carta de Apresentação e Protocolo de Pesquisa para a Pró-Reitoria de Administração e Finanças. Na Carta de Apresentação descreveu-se o objetivo da pesquisa e se ressaltou o sigilo quanto ao nome da instituição e ao tratamento dos dados. No Protocolo de Pesquisa apresentou-se o problema de pesquisa, a estrutura teórica do trabalho e procedimento de coleta dos dados. Segundo Yin (2010), a Carta de Apresentação e o Protocolo de Pesquisa são elementos fundamentais para condução do estudo de caso e para o aumento da confiabilidade da pesquisa.

A população da pesquisa compreende 46 cursos de graduação que estão em funcionamento e que se configuram como a principal fonte de receitas da Instituição. Inicialmente, excluíram-se 12 cursos de formação tecnológica por possuírem características diferentes dos demais cursos de graduação, como tempo menor de graduação, aproximadamente de 3 anos e meio, e por terem uma entrada por ano. Na sequência, eliminaram-se 15 cursos que também apresentam uma única entrada por ano para não prejudicar a comparabilidade de eficiência financeira com os demais cursos que têm duas entradas por ano. Em seguida, eliminaram-se 5 cursos que não estão em pleno funcionamento, por ainda não terem formado a primeira turma. Tal procedimento é necessário visto que a 
estrutura de gastos dos cursos não está totalmente efetivada e, por isso, poderia prejudicar a comparabilidade da eficiência financeira. Por fim, a amostra do estudo totalizou 14 cursos de graduação com formação tipo bacharelado/licenciatura que possuem todas as fases implantadas da matriz curricular e que possibilitam duas entradas anuais. Esses cursos representam $75 \%$ da receita líquida dos cursos de graduação da Instituição.

O Quadro 1 apresenta as variáveis financeiras da pesquisa solicitadas para cada curso de graduação.

\begin{tabular}{|c|l|l|}
\hline Tipo & \multicolumn{1}{|c|}{ Variáveis } & \multicolumn{1}{c|}{ Características } \\
\hline Produto & Receita Líquida por aluno (RL) & Receita líquida dos serviços prestados \\
\hline $\begin{array}{l}\text { Despesas com Pessoal por } \\
\text { aluno (DP) }\end{array}$ & $\begin{array}{l}\text { Gastos com salários, benefícios e encargos de } \\
\text { professores e colaboradores técnico-administrativos } \\
\text { e com a prestação de serviços de terceiros de caráter } \\
\text { permanente. }\end{array}$ \\
\hline Insumos & $\begin{array}{l}\text { Despesas Administrativas por } \\
\text { aluno (DA) }\end{array}$ & $\begin{array}{l}\text { Gastos com materiais de uso e consumo, viagens de } \\
\text { estudos serviços de reprografia, bolsas } \\
\text { institucionais, anuidades e taxas diversas, telefone, } \\
\text { serviços de terceiros entre outros. }\end{array}$ \\
\cline { 2 - 3 } & $\begin{array}{l}\text { Despesas com Filantropia por } \\
\text { aluno (DF) } \\
\text { Outras Despesas por aluno } \\
\text { (OD) }\end{array}$ & $\begin{array}{l}\text { Gastos com bolsas de graduação de acordo com } \\
\text { critérios legais de filantropia. }\end{array}$ \\
$\begin{array}{l}\text { Gastos com perdas de recebíveis e com a provisão } \\
\text { para devedores duvidosos }\end{array}$ \\
\hline
\end{tabular}

Quadro 1 Variáveis Financeiras.

Fonte: Elaborado pelos autores.

Os produtos são as receitas líquidas obtidas pelos cursos de graduação, por meio dos esforços dispendidos. Os insumos representam os esforços dispendidos pelos cursos de graduação para gerar receitas para a Instituição. As variáveis financeiras representam a razão entre receitas ou despesas e o número de alunos matriculados em cada curso.

Para avaliar a eficiência financeira dos cursos de graduação aplicou-se a técnica de Análise Envoltória de Dados (DEA) que segundo Mello et al. (2005) é uma técnica programação linear matemática utilizada para a medir a eficiência de processos que utilizam múltiplos insumos (inputs) e que tenham como resultados múltiplos produtos (outputs). O objetivo da DEA é comparar certo número de unidades organizacionais (Decision Making Unit - DMU) que realizam processos similares, mas que se diferenciam nas quantidades de insumos consumidos e produtos gerados.

A comparação de produtividade entre as DMUs gera uma medida de eficiência de produtividade, resultante da relação produtos/insumos. A DEA produz como medida de eficiência um indicador que varia entre 0 e 1 ou de $0 \%$ a $100 \%$. Logo, uma DMU é 
considerada eficiente quanto o indicador for igual a 1, ou seja, está posicionada na Fronteira de Eficiência (máxima produtividade). Quanto mais próximo de 1 mais eficiente é considera a DMU, caso contrário menos eficiente. Mello et al. (2005) observam que existem duas maneiras básicas de uma DMU ineficiente se tornar eficiente, a primeira é reduzir insumos e manter constante o nível de produtos (orientação ao insumo) e a segunda é manter o nível constante de insumos e maximizar produtos (orientação ao produto). Para possibilitar tais ações a DEA fornece parâmetros (benchmark) para as DMUs ineficientes.

A técnica DEA possui duas modelagens clássicas, que são CCR de Charnes, Cooper e Rhodes (1978) e BCC de Banker, Charnes e Cooper (1984). O modelo CCR mensura a eficiência técnica, com a comparação entre todas as DMUs. Tem por base Retornos Constante de Escala (Constant Returns to Scale - CRS); uma vez que qualquer variação nos insumos produz variação constante ou proporcional nos produtos (CHARNES; COOPER; RHODES, 1978, ALI; SEIFORD, 1993, LINS; MEZA, 2000, MELLO et al., 2005). O modelo BCC mensura a eficiência gerencial, com a comparação entre as DMUs de porte semelhante. Tem por base Retornos Variáveis de Escala (Variable Returns to Scale - VRS); uma vez que os valores de insumos e de produtos podem assumir valores de retornos crescentes ou decrescente de escala, sem uma proporcionalidade entre eles (BANKER; CHARNES; COOPER, 1984; ALI; SEIFORD, 1993, LINS; MEZA, 2000; MELLO et al., 2005).

Para fins deste estudo utilizou-se o modelo BCC que permite a comparação de eficiência gerencial entre DMUs com variáveis de montantes distintos. Essa escolha tem por base a condição de que os cursos de graduação (DMUs) possuem montantes diferentes de receitas e despesas devido às necessidades de estrutura didático-pedagógica para cada área de formação. Outra justificativa é que nem sempre o aumento de receitas (produtos) possui relação proporcional com o aumento dos gastos operacionais (insumos). O modelo BCC utilizado foi o orientado ao produto (outputs), pois não se procura alterar o montante dos gastos operacionais que são necessários para a realização de atividades didático-pedagógicas, mas maximizar as receitas dos cursos de graduação. O software utilizado no estudo foi o MaxDEA Basic ${ }^{\circledR}$ versão 6.4 para avaliação da eficiência financeira.

\section{DESCRIÇÃO E ANÁLISE DOS RESULTADOS}

O Quadro 2 mostra os montantes de receitas e despesas de acordo com a estrutura operacional por curso. 


\section{ANÁLISE ENVOLTÓRIA DE DADOS PARA AVALIAÇÃO DA EFICIÊNCIA FINANCEIRA DOS CURSOS DE GRADUAÇÃO DE UMA IES COMUNITÁRIA \\ DOI: http://dx.doi.org/10.5007/1983-4535.2017v10n2p91}

\begin{tabular}{|c|c|c|c|c|c|c|}
\hline \multirow{2}{*}{ Cod. } & \multirow{2}{*}{ Cursos } & Produto & \multicolumn{4}{|c|}{ Insumos } \\
\hline & & RL & DP & DA & $\mathrm{DF}$ & OD \\
\hline 4500CSA & Administração & $4.093,52$ & $1.167,76$ & 67,80 & 832,52 & 1,65 \\
\hline $1700 \mathrm{CSA}$ & Adm./Com. Exterior & $4.168,34$ & $1.141,09$ & 35,11 & $1.112,82$ & 4,29 \\
\hline 4300CSA & Ciências Contábeis & $4.061,19$ & $1.213,98$ & 40,45 & 897,67 & 1,91 \\
\hline 4600CSA & Ciências Jurídicas & $4.577,07$ & $1.437,31$ & 57,95 & 575,30 & 1,05 \\
\hline 6600CET & Arquit. e Urbanismo & $8.782,81$ & $2.686,41$ & 117,87 & $1.466,61$ & 2,36 \\
\hline 6700CET & Ciências da Computação & $4.506,67$ & $1.549,38$ & 89,49 & $1.164,03$ & 0,86 \\
\hline 2780CET & Engenharia Civil & $4.658,27$ & $1.122,98$ & 24,09 & 664,06 & 0,41 \\
\hline 1030SAU & Enfermagem & $6.177,63$ & $3.412,81$ & 216,42 & $1.857,29$ & 3,27 \\
\hline 1060SAU & Farmácia & $12.709,50$ & $3.619,63$ & 174,43 & $4.181,93$ & 4,70 \\
\hline 1080SAU & Fisioterapia & $6.366,37$ & $2.198,02$ & 46,53 & $2.202,53$ & \\
\hline $1120 \mathrm{SAU}$ & Medicina & $21.141,26$ & $8.935,13$ & 217,27 & $1.713,61$ & 0,07 \\
\hline $1200 \mathrm{SAU}$ & Psicologia & $4.481,13$ & $1.807,53$ & 76,55 & 936,02 & 0,85 \\
\hline $1400 \mathrm{HCE}$ & Artes Visuais & $4.344,41$ & $1.988,21$ & 177,34 & $1.788,73$ & 2,60 \\
\hline $1420 \mathrm{HCE}$ & Educação Física & $2.594,48$ & $1.007,24$ & 66,71 & 961,88 & \\
\hline & Total & $92.662,66$ & $33.287,49$ & $1.408,02$ & $20.355,00$ & 24,00 \\
\hline
\end{tabular}

Quadro 2 Demonstração do Resultado Operacional (em R\$/aluno).

Fonte: Elaborado pelos autores.

A estrutura de operacional da instituição evidencia que os cursos com maiores níveis representatividade são: a) Medicina - Receita Líquida (22,82\%), Despesas com Pessoal (26,84\%), Despesas Administrativas (15,43\%), Despesas com Filantropia (8,42\%) e Outras Despesas (0,28\%); b) Farmácia - Receita Líquida (13,72\%), Despesas com Pessoal (10,87\%), Despesas Administrativas (12,79\%), Despesas com Filantropia (20,54\%) e Outras Despesas $(19,56 \%)$; c) Arquitetura e Urbanismo - Receita Líquida (9,48\%), Despesas com Pessoal (8,07\%), Despesas Administrativas (8,37\%), Despesas com Filantropia (7,21\%) e Outras Despesas (9,82\%); e d) Enfermagem - Receita Líquida (6,67\%), Despesas com Pessoal (10,25\%), Despesas Administrativas (15,37\%), Despesas com Filantropia (9,12\%) e Outras Despesas $(13,61 \%)$.

O curso de Medicina possui carga horária integral com matriz curricular de 6 anos de duração e atende aproximadamente 500 alunos. O curso de Farmácia oferece vagas nos períodos matutino e noturno com matriz curricular de 5 anos e atende aproximadamente 290 alunos. O curso de Arquitetura e Urbanismo oferta vagas no período vespertino com matriz curricular de 5 anos e atende aproximadamente 290 alunos. O curso de Enfermagem tem matriz curricular de 4 anos e meio e oferece vagas nos períodos vespertino e noturno e conta com aproximadamente 270 alunos.

Esses cursos são representativos na estrutura operacional da Instituição: a) por necessitarem de uma quantidade significativa de professores para atuar nas atividades em sala de aula, laboratórios, ateliês de projetos, estágio/supervisão de alunos, b) por utilizarem 


\section{ANÁLISE ENVOLTÓRIA DE DADOS PARA AVALIAÇÃO DA EFICIÊNCIA FINANCEIRA DOS CURSOS DE GRADUAÇÃO DE UMA IES COMUNITÁRIA \\ DOI: http://dx.doi.org/10.5007/1983-4535.2017v10n2p91}

materiais de uso e consumo específicos para as atividades que envolvem o ensino da medicina, farmacologia, projetos arquitetônicos e serviços de reprografia, c) por requererem gastos com a manutenção de laboratórios de pesquisas, equipamentos laboratoriais, ateliês de projetos arquitetônicos e atividades de extensão e d) por disponibilizarem bolsas de estudos institucionais e filantrópicas.

O Quadro 2 também aponta os cursos com menores níveis de representatividade na estrutura operacional, que são: Engenharia Civil - Receita Líquida (5,03\%), Despesas com Pessoal (3,37\%), Despesas Administrativas (1,71\%), Despesas com Filantropia (3,26\%) e Outras Despesas (1,71\%) e b) Educação Física - Receita Líquida (2,80\%), Despesas com Pessoal (3,03\%), Despesas Administrativas (4,74\%), Despesas com Filantropia (4,73\%) e Outras Despesas $(0,00 \%)$. Esses cursos demandam por uma estrutura operacional de menor porte e possuem como principais gastos as despesas com salários, benefícios e encargos de professores, viagens e estadas, viagens de estudo, material de uso e consumo, serviços de reprografia, bolsas de estudos institucionais e filantrópicas.

A partir das variáveis financeiras da estrutura operacional dos cursos, aplicou-se a técnica DEA para mensurar a eficiência financeira. O Quadro 3 mostra os indicadores de eficiência obtidos e respectivos benchmarks.

\begin{tabular}{|c|c|c|c|}
\hline DMU & Score & Benchmark (Lambda) & Citação \\
\hline Arquit. e Urbanismo & 1 & Arquit. e Urbanismo $(1,000000)$ & 3 \\
\hline Ciências Jurídicas & 1 & Ciências Jurídicas $(1,000000)$ & 0 \\
\hline Educação Física & 1 & Educação Física $(1,000000)$ & 0 \\
\hline Engenharia Civil & 1 & Engenharia Civil $(1,000000)$ & 6 \\
\hline Farmácia & 1 & Farmácia $(1,000000)$ & 7 \\
\hline Fisioterapia & 1 & Fisioterapia $(1,000000)$ & 0 \\
\hline Medicina & 1 & Medicina $(1,000000)$ & 3 \\
\hline Adm. Com. Exterior & 0,883746 & Engenharia Civil $(0,992746)$; Farmácia $(0,007254)$ & 0 \\
\hline Administração & 0,852341 & Engenharia Civil $(0,982064)$; Farmácia $(0,017936)$ & 0 \\
\hline Ciências Contábeis & 0,820159 & Engenharia Civil $(0,963553)$; Farmácia $(0,036447)$ & 0 \\
\hline Ciências da Computação & 0,769526 & $\begin{array}{l}\text { Engenharia Civil (0,872452); Farmácia }(0,107238) \text {; } \\
\text { Medicina }(0,020309)\end{array}$ & 0 \\
\hline Psicologia & 0,709503 & $\begin{array}{l}\text { Arquit. e Urbanismo }(0,181499) \text {; Engenharia Civil } \\
(0,751709) \text {; Farmácia }(0,022764) \text {; Medicina }(0,044028)\end{array}$ & 0 \\
\hline Enfermagem & 0,588307 & $\begin{array}{l}\text { Arquit. e Urbanismo }(0,768793) \text {; Farmácia }(0,135142) \text {; } \\
\text { Medicina }(0,096066)\end{array}$ & 0 \\
\hline Artes Visuais & 0,588148 & $\begin{array}{l}\text { Arquit. e Urbanismo }(0,067465) ; \text { Engenharia Civil } \\
(0,628225) \text {; Farmácia }(0,304310)\end{array}$ & 0 \\
\hline
\end{tabular}

Quadro 3 Indicadores de Eficiência e cursos de referências.

Fonte: Elaborado pelos autores. 


\section{ANÁLISE ENVOLTÓRIA DE DADOS PARA AVALIAÇÃO DA EFICIÊNCIA FINANCEIRA DOS CURSOS \\ DE GRADUAÇÃO DE UMA IES COMUNITÁRIA \\ DOI: http://dx.doi.org/10.5007/1983-4535.2017v10n2p91}

Os cursos que atingiram o nível máximo de eficiência $(1,00)$, ou seja, estão localizados na fronteira de eficiência foram: Arquitetura e Urbanismo, Ciências Jurídicas, Educação Física, Engenharia Civil, Farmácia, Fisioterapia e Medicina. Por sua vez, os principais cursos ineficientes foram: Artes Visuais (0,588148) e Enfermagem (0,588307).

Segundo a quantidade de alunos matriculados, os cursos podem ser classificados, como: a) grande porte (acima de 600 alunos) - Administração, Ciências Contábeis, Ciências Jurídicas e Engenharia Civil; b) médio porte (entre 300 a 599 alunos) - Administração Comércio Exterior, Educação Física, Medicina e Psicologia; e c) pequeno porte (até 299 alunos) - Arquitetura e Urbanismo, Artes Visuais, Ciências da Computação, Enfermagem, Farmácia e Fisioterapia. De acordo com essa classificação e os resultados da DEA, no Quadro 3, percebe-se que a eficiente financeira está presente em diversos cursos da Instituição, independentemente do porte da estrutura operacional.

Outro resultado fornecido pela DEA é a quantidade de citação em que um curso eficiente foi utilizado como referência (benchmark) por outro curso não eficiente. Os cursos de Farmácia e Engenharia Civil foram os mais citados como referência pelos cursos ineficientes com o total de 7 e 6 citações, respectivamente. Cabe observar que o curso de Engenharia Civil se destaca em sua estrutura operacional por a) oferecer vagas nos períodos matutino e noturno com matriz curricular de 5 anos; b) atender aproximadamente 780 alunos e c) ter uma receita com representatividade significativa $(5,03 \%)$ e gastos operacionais com baixa representatividade tais como Despesas com Pessoal (3,37\%), Despesas Administrativas (1,71\%), Despesas com Filantropia (3,26\%) e Outras Despesas (1,71\%). Portanto, tais aspectos resultam em maiores ganhos operacionais em comparação a outros cursos.

Para buscar a eficiência financeira $(1,00)$, os cursos ineficientes devem observar os cursos indicados como referência (benchmark). Como exemplo, o curso de Artes Visuais 1400HCE possui um score de 0,588148 e para buscar a eficiência deve utilizar como referências os cursos de Arquitetura e Urbanismo - 6600CET (0,067465), Engenharia Civil 2780CET (0,628225) e Farmácia - 1060SAU (0,304310).

O Quadro 4 mostra as metas a serem perseguidas pelo curso de Artes Visuais. 


\section{ANÁLISE ENVOLTÓRIA DE DADOS PARA AVALIAÇÃO DA EFICIÊNCIA FINANCEIRA DOS CURSOS DE GRADUAÇÃO DE UMA IES COMUNITÁRIA \\ DOI: http://dx.doi.org/10.5007/1983-4535.2017v10n2p91}

\begin{tabular}{|l|r|r|r|r|r|r|r|}
\hline \multirow{2}{*}{ Variáveis } & \multicolumn{1}{c|}{ Curso } & \multicolumn{2}{c|}{ Cursos - Benchmark } & \multicolumn{3}{c|}{ Metas } \\
\cline { 2 - 8 } & \multicolumn{1}{c|}{$1400 \mathrm{HCE}$} & $6600 \mathrm{CET}$ & \multicolumn{1}{c|}{ 2780CET } & \multicolumn{1}{c|}{$1060 \mathrm{SAU}$} & \multicolumn{1}{c|}{ Total } & Dif. (R\$) & Dif. (\%) \\
\hline Lambda & 0,588148 & 0,067465 & 0,628225 & 0,304310 & 1,000000 & & \\
\hline Receita Líquida & $4.344,41$ & $8.782,81$ & $4.658,27$ & $12.709,50$ & $7.386,60$ & $3.042,19$ & $70,03 \%$ \\
\hline Desp.com Pessoal & $1.988,21$ & $2.686,41$ & $1.122,98$ & $3.619,63$ & $1.988,21$ & 0,00 & $0,00 \%$ \\
\hline Desp. Administrativas & 177,34 & 117,87 & 24,09 & 174,43 & 76,17 & $(101,17)$ & $-57,05 \%$ \\
\hline Desp. com Filantropia & $1.788,73$ & $1.466,61$ & 664,06 & $4.181,93$ & $1.788,73$ & 0,00 & $0,00 \%$ \\
\hline Outras Despesas & 2,60 & 2,36 & 0,41 & 4,70 & 1,85 & $(0,76)$ & $-29,05 \%$ \\
\hline
\end{tabular}

Quadro 4 Metas de Eficiência para cursos de Artes Visuais.

Fonte: Elaborado pelos autores.

De acordo com a estrutura operacional de cada curso de referência indicado, calcula-se a proporção financeira com base nos Lambdas e somam-se os resultados para a obtenção da meta total a ser atingida. Na sequência, realizam-se as diferenças em valor e em percentual entre a meta total e as variáveis do curso. Os resultados indicam que para o curso de Artes Visuais - 1400HCE atingir a eficiência deve aumentar a Receita Líquida em R\$ 3.042,19 $(70,03 \%)$ e diminuir as Despesas Administrativas em $\mathrm{R} \$ 101,17(-57,05 \%)$ e as Outras Despesas em R \$ 0,76 (-29,05\%).

De acordo com a lógica de cálculo de metas de eficiência exposta no Quadro 4, o Quadro 5 apresenta a síntese de metas a serem atingidas pelos cursos ineficientes em percentual.

\begin{tabular}{|l|r|r|r|r|r|r|}
\hline \multicolumn{1}{|c|}{ Variáveis } & \multicolumn{7}{|c|}{ Cursos - Metas (\%) } \\
\hline & 1700 CSA & 4500 CSA & 4300CSA & 6700 CET & 1030 SAU & 1200 SAU \\
\hline Receita Líquida & $13,15 \%$ & $17,32 \%$ & $21,93 \%$ & $29,95 \%$ & $69,98 \%$ & $40,94 \%$ \\
\hline Desp.com Pessoal & $0,00 \%$ & $0,00 \%$ & $0,00 \%$ & $0,00 \%$ & $0,00 \%$ & $0,00 \%$ \\
\hline Desp. Administrativas & $-28,29 \%$ & $-60,49 \%$ & $-26,90 \%$ & $-50,68 \%$ & $-37,59 \%$ & $-30,71 \%$ \\
\hline Desp. com Filantropia & $-38,03 \%$ & $-12,66 \%$ & $-11,74 \%$ & $-8,71 \%$ & $0,00 \%$ & $0,00 \%$ \\
\hline Outras Despesas & $-89,69 \%$ & $-70,44 \%$ & $-70,33 \%$ & $0,00 \%$ & $-24,92 \%$ & $0,00 \%$ \\
\hline
\end{tabular}

Quadro 5 Metas da estrutura operacional dos cursos ineficientes.

Fonte: Elaborado pelos autores.

As metas gerenciais sugeridas pelo DEA indicam a necessidade de aumento de receitas e diminuição de despesas administrativas, com filantropia e de outras despesas operacionais. Em relação às receitas, observa-se que para buscar o aumento de receitas é preciso captar novos alunos, elaborar estratégias para retenção de alunos e verificar a possibilidade de aumento dos preços de venda no serviço prestado. Cabe salientar que também é necessário conhecer o potencial socioeconômico da região e dos alunos com vistas a identificar a viabilidade de aumento de receitas. 


\section{ANÁLISE ENVOLTÓRIA DE DADOS PARA AVALIAÇÃO DA EFICIÊNCIA FINANCEIRA DOS CURSOS \\ DE GRADUAÇÃO DE UMA IES COMUNITÁRIA \\ DOI: http://dx.doi.org/10.5007/1983-4535.2017v10n2p91}

Por outro lado, para diminuir as despesas operacionais, os gestores devem desenvolver uma postura crítica para análise de gastos, principalmente os administrativos, com o objetivo de constatar a "real" necessidade e evitar desperdícios, sem prejudicar a qualidade dos serviços prestados e o atendimento aos critérios legais de filantropia. As despesas mais representativas em relação à receita líquida são: Bolsas Filantrópicas (19,20\%), Bolsas Institucionais (0,43\%), Material de Uso e Consumo (0,28\%), Serviços de Reprografia $(0,15 \%)$, Anuidades e Taxas Diversas (0,11\%), Despesas Bancárias $(0,11 \%)$ e Viagens de Estudo (0,08\%). Cabe ressaltar que as despesas com Bolsas Filantrópicas são necessárias para a manutenção da condição de universidade comunitária e da utilização de benefícios tributários. Por isso, a Instituição para atendimento desses aspectos, tem a obrigatoriedade, por força de lei, de destinar $20 \%$ de sua receita líquida como bolsas de estudos para alunos enquadrados em critérios de gratuidade.

Os estudos anteriores reforçam a aplicabilidade da DEA para mensuração da eficiência organizacional em universidades. Em estudos com características similares, Alencastro e Fochezatto (2006) e Giacomello e Oliveira (2014) também sugerem o aumento de receitas, mas observam que isso está relacionado à quantidade alunos matriculados, taxa de evasão acadêmica, aumento do número de alunos e fatores macroeconômicos. O resultado do estudo de Justino, Gomes Jr. e Gomes (2014) diverge da presente pesquisa, uma vez que não se encontrou a necessidade de redução de despesas com pessoal para os cursos ineficientes melhorarem sua eficiência.

De modo geral, os resultados fornecem evidencias da situação organizacional e possibilitam ações gerenciais de curto e longo prazo para promover a continuidade das operações (CATELLI, 2001; GASPARETTO, 2004; ATKINSON et al., 2000; MATARAZZO, 2010; ASSAF NETO, 2012). Os indicadores obtidos pela DEA proporcionam uma reflexão sobre a eficiência financeira dos cursos, corroboram para a gestão do negócio e propiciam discussões fundamentadas para o alinhamento entre os objetivos acadêmicos, financeiros, econômicos, sociais e institucionais.

\section{CONCLUSÃO}

As universidades desempenham um papel relevante para o desenvolvimento da sociedade. Sua função é promover desenvolvimento intelectual, tecnológico e econômico do país. As pressões do ambiente econômico, principalmente para as universidades privadas, 
obrigam as instituições a buscar por instrumentos gerencias que auxiliem a avaliação do desempenho organizacional. Nesse contexto, o objetivo geral do artigo foi avaliar a eficiência financeira dos cursos de graduação de uma Instituição de Ensino Superior (IES) comunitária do sul do Brasil, por meio da técnica de técnica de Análise Envoltória de Dados (DEA).

Os resultados da pesquisa mostraram que os cursos de Medicina, Farmácia, Arquitetura e Urbanismo e Enfermagem possuem os maiores níveis de representatividade de receita e despesas na estrutura operacional da Instituição. Esses cursos se destacam por possuir uma matriz curricular com duração média de 5 anos e que demanda por uma infraestrutura didático-pedagógica quer requer laboratórios, ateliês de projetos, estágios curriculares e consumo de materiais técnicos para as atividades de ensino.

Com a aplicação da técnica DEA, 7 cursos (50\%) foram considerados eficientes (Arquitetura e Urbanismo, Ciências Jurídicas, Educação Física, Engenharia Civil, Farmácia, Fisioterapia e Medicina) e 7 cursos (50\%) foram considerados ineficientes (Administração, Administração Comércio Exterior, Artes Visuais, Ciências da Computação, Ciências Contábeis, Enfermagem e Psicologia). Cabe mencionar que cursos de Administração Comércio Exterior (0,883746), Administração (0,852341), e Ciências Contábeis $(0,820159)$ tiveram pontuação próxima à fronteira de eficiência $(1,00)$. Por outro lado, os cursos mais ineficientes foram Enfermagem $(0,588307)$ e Artes Visuais $(0,588148)$. O resultado da DEA revela que para buscar a eficiência financeira, os cursos ineficientes necessitam aumentar receitas e diminuir despesas administrativas, além de outras despesas operacionais.

Conclui-se que as ações gerenciais indicadas pela DEA necessitam de uma reflexão crítica por parte dos gestores. A primeira ação, que envolve a possibilidade de aumento de receitas, está vinculada, principalmente, às condições de infraestrutura universitária disponível e aos fatores socioeconômicos da região e de potenciais alunos; além da observância dos preços praticados por cursos concorrentes. A segunda ação, relativa aos gastos operacionais, cabe uma discussão sobre a efetiva necessidade de realização da despesa e sobre o desenvolvimento de políticas gerencias que aumentem o controle de gastos para evitar desperdícios, abusos e excessos de consumo sem justificativas cabíveis. A partir dessas reflexões gerenciais, os gestores podem implementar medidas que proporcionem melhorias na eficiência organizacional e que promovam a sustentabilidade financeira para garantir a execução das políticas de ensino, pesquisa e extensão. 


\section{REFERÊNCIAS}

ALENCASTRO, L. D.; FOCHEZATTO, A. Eficiência técnica na gestão de recursos em instituições privadas de ensino superior. Análise - Revista de Administração da PUCRS, v. 17, n. 2, p. $234-242$, jul./dez. 2006.

ALI, A. I.; SEIFORD, L. M. The mathematical programming approach to efficiency analysis, In: FRIED, H. O.; LOVELL, C. A. K.; SCHMIDT, S. S. (Org.). Measurement of productive efficiency: techniques and applications. New York: Oxford University Press, 1993. p. 120159.

ANDRADE, A. R. A universidade como organização complexa. Revista de Negócios. Blumenau, v. 7, n. 3, p. 15-28, jul./set. 2002.

ASSAF NETO, A. Finanças corporativas e valor. 6. ed. São Paulo: Atlas, 2012.

ASSOCIAÇÃO BRASILEIRA DE MANTENEDORAS DO ENSINO SUPERIOR (ABMES). Diagnóstico das pequenas e médias instituições de Ensino Superior privadas no Brasil: indicações para melhoria da competitividade. Estudos - Revista da Associação Brasileira de Mantenedoras de Ensino Superior. Brasília, v. 29, n. 41, p. 15 - 112, mar. 2014.

ATKINSON, A. A. et al. Contabilidade gerencial. São Paulo: Atlas, 2000.

BANKER, R.D.; CHARNES, A.; COOPER, W.W. Some models for estimating technical scale inefficiencies in data envelopment analysis. Management Science, v. 30, n. 9, p. 10781092, september, 1984.

BRASIL. Lei n. 9.394, de 20 de dezembro de 1996. Estabelece as diretrizes e bases da educação nacional. http://www.planalto.gov.br/ccivil 03/leis/19394.htm Acesso em: 21 de janeiro 2015.

. Lei n. 12.020, de 27 de agosto de 2009. Dá nova redação ao inciso II do caput do art. 20 da Lei no 9.394, de 20 de dezembro de 1996, que estabelece as diretrizes e bases da educação nacional, para modificar o rol de instituições de ensino comunitárias.

$<$ http://www.planalto.gov.br/ccivil_03/_Ato2007-2010/2009/Lei/L12020.html > Acesso em: 21 de janeiro 2015.

Decreto n. 5.773, de 9 de maio de 2006. Dispõe sobre o exercício das funções de regulação, supervisão e avaliação de instituições de educação superior e cursos superiores de graduação e sequenciais no sistema federal de ensino.

http://www.planalto.gov.br/ccivil 03/ Ato2004-2006/2006/Decreto/D5773.htm\#art79 Acesso em: 21 de janeiro de 2015.

CAVALCANTE, S. M.; ANDRIOLA, W. Avaliação da eficiência dos cursos de graduação da Universidade Federal do Ceará (UFC) através da Análise Envoltória de Dados (DEA). Revista Iberoamericana de Evaluación Educativa, v. 5, n. 3, p. 291 - 314, 2012. 


\section{ANÁLISE ENVOLTÓRIA DE DADOS PARA AVALIAÇÃO DA EFICIÊNCIA FINANCEIRA DOS CURSOS \\ DE GRADUAÇÃO DE UMA IES COMUNITÁRIA \\ DOI: http://dx.doi.org/10.5007/1983-4535.2017v10n2p91}

CHARNES, A.; COOPER, W.W.; RHODES, E. Measuring the efficiency of decision making units. European Journal of Operational Research, v. 2, n. 6, p. 429-444, november, 1978.

CRUZ, J. A. W. et al. Avaliação de desempenho no terceiro setor: uma abordagem teórica de strategic accounts. Revista Brasileira de Estratégia - REBRAE, Curitiba, v. 2, n. 1, p. 11-26, jan./abr. 2009.

FLICK, U. Qualidade na pesquisa qualitativa. Porto Alegre: Artmed, 2009.

GALVÃO, H. M.; CORRÊA, H. L.; ALVES, J. L. Modelo de avaliação de desempenho global para instituição de ensino superior. Revista Administração - UFSM, Santa Maria, v. 4, n. 3, p. 425-441, set./dez. 2011.

GASPARETTO, V. O papel da contabilidade no provimento de informações para a avaliação do desempenho empresarial. Revista Contemporânea de Contabilidade, v. 1, n. 2, p. 109-122, jul./dez. 2004.

GIACOMELLO, C. P.; OLIVEIRA, R. L. Análise Envoltória de Dados (DEA): uma proposta para avaliação de desempenho de unidades acadêmicas de uma universidade. Revista da Gestão Universitária da América Latina - GUAL. Florianópolis, v. 7, n. 2, p. 130-151, mai. 2014

HENDRIKSEN, E. S.; VAN BREDA, M. F. Teoria da contabilidade. São Paulo: Atlas, 1999.

IUDÍCIBUS, S. Teoria da contabilidade. 10. ed. São Paulo: Atlas, 2010.

JUSTINO, D. A.; GOMES Jr., S. F.; GOMES, A. R. Avaliação preliminar dos cursos de graduação de uma instituição de ensino superior privada utilizando análise envoltória de dados e restrições aos pesos. Revista da Escola de Engenharia da UFF - ENGEVISTA, v. 16, n. 1, p. 111-121, mar. 2014.

KAPLAN, R. S, NORTON, D. A estratégia em ação: balanced scorecard. 7. ed. Rio de Janeiro: Editora Campus, 2000.

KLANN, R. C. et al. Avaliação de desempenho das instituições de ensino superior pertencentes à Associação Catarinense das Fundações Educacionais (Acafe). Contabilidade, Gestão e Governança, Brasília, v. 15, n. 3, p. 71 - 87, set./dez. 2012.

LINS, M.P.E.; MEZA, L. A. Análise Envoltória de Dados e perspectivas de integração no ambiente de Apoio à Decisão. Rio de Janeiro: Editora COPPE/UFRJ, 2000.

MARTINS, G. A.; THEÓPHILO, C. R. Metodologia da investigação científica para ciências sociais aplicadas. 2. ed. São Paulo: Atlas, 2009.

MATARAZZO, D. C. Análise financeira de balanços: abordagem geral. 7. ed. São Paulo: Atlas, 2010. 
MELLO et al. Análise envoltória de dados para avaliação de departamento de ensino. Ensaio: avaliação e políticas públicas em educação, Rio de Janeiro, v. 12, n. 42, p. 611 - 622, jan./mar. 2004.

MELLO, J. C. C. B. S. et al. Curso de análise de envoltória de dados. In: SIMPÓSIO BRASILEIRO DE PESQUISA OPERACIONAL, 37., 2005, Gramado, Anais ... Gramado: SOBRAPO, 2005.

PEREIRA, C. A. Avaliação de resultados e desempenhos. In: CATELLI, A. (Coord.). Controladoria: uma abordagem da gestão econômica - GECON. 2. ed. São Paulo: Atlas, 2001.

PESSOA, M. N. M. Gestão das universidades federais brasileiras: um modelo fundamentado no Balanced Scorecard. Florianópolis, 2000. 291 f. Tese (Doutorado) - Engenharia de Produção da Universidade Federal de Santa Catarina, Florianópolis, 2000.

REIS, E. A.; REIS, E. A. Sistemas de informação e tomada de decisão na gestão universitária: um olhar nos indicadores de desempenho de uma instituição de ensino superior. IN:

COLOQUIO DE GESTIÓN UNIVERSITARIA EN AMÉRICAS, 13., 2013, Florianópolis. Anais... Florianópolis: UFSC, 2013.

ROSANO-PEÑA, C. Eficiência e impacto do contexto na gestão através do DEA: o caso da UEG. Produção, v. 22, n. 4, p. 778-787, set./dez. 2012.

SAMPAIO, R. M.; LANIADO, R. N. Uma experiência de mudança da gestão universitária: o percurso ambivalente entre proposições e realizações. Revista de Administração Pública$R A P$, Rio de Janeiro, v. 43, n. 1, p. 151-174, jan./fev. 2009.

SCHMIDT, P.; SANTOS, J. L.; MARTINS, M. A. Avaliação de empresas: foco na análise de desempenho para o usuário interno - teoria e prática. São Paulo: Atlas, 2006.

SLACK, N.; CHAMBERS, S.; JOHNSTON, R. Administração de Produção. 2. ed. São Paulo: Atlas; 2002.

SOLIMAN, M. et al. Modelagem para avaliação da eficiência técnica de unidades universitárias. Gestão da Produção, Operações e Sistemas - GEPROS, Bauru, v. 9, n. 1, p. 69-83, jan./mar. 2014.

YIN, R. K. Estudo de caso: planejamento e métodos. 4. ed. Porto Alegre: Bookman, 2010. 